\title{
Quantitative microbial risk assessment for occupational health of temporary entrants and staffs equipped with various grade PPE and exposed to microbial bioaerosols in two WWTPs
}

\author{
Cheng Yan ${ }^{1} \cdot$ Ya-li Leng ${ }^{1}$ Jun-ting $\mathrm{Wu}^{1}$
}

Received: 14 October 2020 / Accepted: 17 January 2021 / Published online: 15 March 2021

(c) The Author(s), under exclusive licence to Springer-Verlag GmbH, DE part of Springer Nature 2021

\begin{abstract}
Purpose This study was to evaluate the occupational health risks of infection from Gram-negative bacteria and Staphylococcus aureus bioaerosols to temporary entrants and staffs equipped with various grade personal protection equipment (PPE) related to wastewater treatment plants (WWTPs).

Methods This study determined the emission concentrations of Gram-negative bacteria and Staphylococcus aureus bioaerosols from two WWTPs under various aeration modes. Then, a strict quantitative microbial risk assessment (QMRA) was performed on several exposure scenarios associated with occupational health risks of temporary entrants (researchers, visitors, and inspectors) and staffs (field engineer and laboratory technician).

Results Although the bioaerosol concentrations were generally regarded as safe according to existing standards, these bioaerosols' health risks were still unacceptable. The microbial bioaerosols posed considerable infection health risks in WWTPs. These risks were generally above the WHO and US EPA benchmarks. The health risks of females were always smaller than those of male of grown-up age group. Staffs that had been exposed to bioaerosols for a long time were found to have higher health risks compared with temporary entrants. In addition, field engineers equipped with PPE rendered low health risks, thus revealing that wearing PPE could effectively reduce the occupational health risks.

Conclusion This study provided novel data and enriched the knowledge of microbial bioaerosol emission's health risks from various aeration modes in WWTPs. Management decisions could be executed by authorities on the basis of the results of QMRA for field engineers equipped with PPE to reduce the related occupational health risks.
\end{abstract}

Keywords Occupational health · Quantitative microbial risk assessment · Annual infection risks · Disease burden · Bacteria bioaerosol $\cdot$ Wastewater treatment plants

\section{Introduction}

Bioaerosols are aerosols containing particles of biological origin, which have a broad size spectrum $(0.02-100 \mu \mathrm{m})$ (Ariya and Amyot 2004; Dowd and Maier 2000). Bioaerosol particles include plant or animal debris (e.g., pollen, insects, skin); living microorganisms, such as viruses, bacteria, and fungi; as well as fragments or byproducts of microorganisms (Grinshpun and Clark 2005; Reponen 2011). Some evidence

Cheng Yan

cheng_yan@cug.edu.cn

1 School of Environmental Studies, China University of Geosciences, 388 Lumo Road, Wuhan 430074 , People's Republic of China shows that exposure to bioaerosols can be harmful and pose potential occupational health risks related to infection, toxicity, and allergenicity (Douwes et al. 2003; Eduard et al. 2012; Heederik and Mutius 2012). In addition, health risks from bioaerosol exposure can be greatly enhanced by the airborne transmission of infectious agents, such as SARS in 2003, H1N1 in 2009, and COVID-19 in 2020 (Asadi et al. 2020; Hao et al. 2019; Xiao et al. 2004).

The number of wastewater treatment plants (WWTPs) is very large and has increased rapidly in China. A total of 87 WWTPs with a treatment capacity of $4.45 \times 10^{9} \mathrm{~m}^{3} /$ day existed in 1991. Then, this number increased to 2209 WWTPs with a treatment capacity of $4.65 \times 10^{10} \mathrm{~m}^{3} /$ day in 2017 (MOHURD, 2020). However, WWTPs have been recognized as a substantial source of bioaerosols (Brandi et al. 2000). A large number and great diversity of 
pathogenic microorganisms in wastewater can become aerosolized through various aeration modes (e.g., mechanical or blast aeration process) (Fannin et al. 1985; Moazeni et al. 2017). Thus, the bioaerosols formed are capable of infecting humans (particularly for sewage workers at WWTPs) through inhalation, ingestion, or dermal contact, and they may be a potential source of health risks for the exposure population (Brooks et al. 2004; Carducci et al. 2000; Hickey and Parker 1975). Several works have shown that the occurrence of certain work-related symptoms (a particular type of illness called "sewage worker's syndrome") are frequently present among sewage workers and temporary entrants (Nethercott and Holness 1988; Rylander 2002; Thorn et al. 2002). The potential for adverse effects from bioaerosol emissions in WWTPs is significant (Carducci et al. 2008; Glassmeyer et al. 2005). Therefore, quantifiably evaluating the potential occupational health risks of microbial bioaerosols arising from WWTPs under various scenarios is critical.

Quantitative microbial risk assessment (QMRA) is a valuable approach to understanding and estimating the health risks posed by the microbial bioaerosols emitted from WWTPs (Abia et al. 2016; Yillia et al. 2009). The QMRA framework consists of four fundamental steps: hazard identification, exposure assessment, dose-response assessment, and risk characterization (Codex Alimentarius Commission, 1999; U.S. EPA 2007). Two of the most authoritative and widely used health risk benchmarks are used to evaluate whether the risk calculated by the QMRA is acceptable or not (Blanky et al. 2017). These benchmarks are the acceptable annual infection risk level proposed by the U.S. EPA $\left[\leq 10^{-4}\right.$ infection cases per-person-per-year (pppy)] and the acceptable disease burden level proposed by WHO $\left(\leq 10^{-6}\right.$ DALYs pppy ${ }^{-1}$ ) (U.S. EPA 2005; World Health Organization 2008).

Studies have been conducted to evaluate the health risks of bioaerosols by determining the concentrations of microbial bioaerosols from WWTPs (Pascual et al. 2003; Pillai and Ricke 2002; Ranalli et al. 2000). Orsini et al. (2002) analyzed samples of bioaerosols collected from a turbine aeration tank in a WWTP and evaluated the bioaerosol risk for sewage workers. Stellacci et al. (2010) studied the emission of Cryptosporidium, Campylobacter, and Rotavirus bioaerosols from WWTPs and assessed the potential health effects of these particles on the neighborhood. In another study, Carducci et al. (2018) estimated the human adenovirus health risk due to bioaerosol exposure in WWTPs and calculated the exposure limits considering four different risk levels. Furthermore, Pasalari et al. (2019) measured the concentrations of Rotavirus and Norovirus bioaerosols in a WWTP equipped with a microporous aeration tank and found high health risks for workers and nearby residents. However, a number of studies have only focused on bioaerosol emissions associated with a single aeration mode, and information on bioaerosol emissions in different aeration modes is scarce (Fathi et al. 2017; Karra and Katsivela 2007; Niazi et al. 2015). Another research gap is that the health risks of microbial bioaerosols in various exposure scenarios remain poorly investigated, particularly in China. Moreover, the health risks of temporary entrants have often been overlooked and insufficiently inspected systematically. In addition, information about the health risks of the exposure population equipped with masks is inadequate (Konda et al. 2020). Consequently, a serious open question remains on how to conduct a comprehensive understanding of the effects of aeration modes on bioaerosol emissions and the quantifiable evaluation of the health risks of bioaerosols for various exposure scenarios in WWTPs.

After determining the emission concentrations of microbial bioaerosols (Gram-negative bacteria and Staphylococcus aureus bioaerosols) from two WWTPs under various aeration modes, this research focuses on the systematically quantitatively evaluates the bioaerosols' occupational health risks for several exposure scenarios by comparing them with the benchmarks to discuss the implications of these risks. The health risks of exposed staffs field engineers equipped with a series of personal protection equipment (PPE) are strictly evaluated. The current research enriches the knowledge bases of microbial bioaerosols emissions from various aeration modes in WWTPs and then provides an advanced understanding of human health risks in various exposure scenarios. These results can inform efforts to establish rational management recommendations for reducing occupational health risks.

\section{Method and materials}

\section{Description of the wastewater treatment plants}

This study was conducted at two different wastewater treatment plants (WWTPs) (plant A and plant B) located in central China, which were characterized by various aeration modes. They both used activated sludge to treat wastewater and operated continuously throughout the year. Plant A was equipped with parallel connected rotating disc aeration (phase one) and microporous aeration (phase two) tanks with equally assigned inflows of $100,000 \mathrm{~m}^{3} /$ day. Plant B was equipped with parallel connected inverted umbrella aeration (Phase one) and microporous aeration (Phase two) tanks with equally assigned inflows of 200,000 $\mathrm{m}^{3} /$ day. Figure 1 presents schematic diagrams of wastewater treatment process of these two WWTPs. The inlet water quality of the plants is presented in Supplementary 

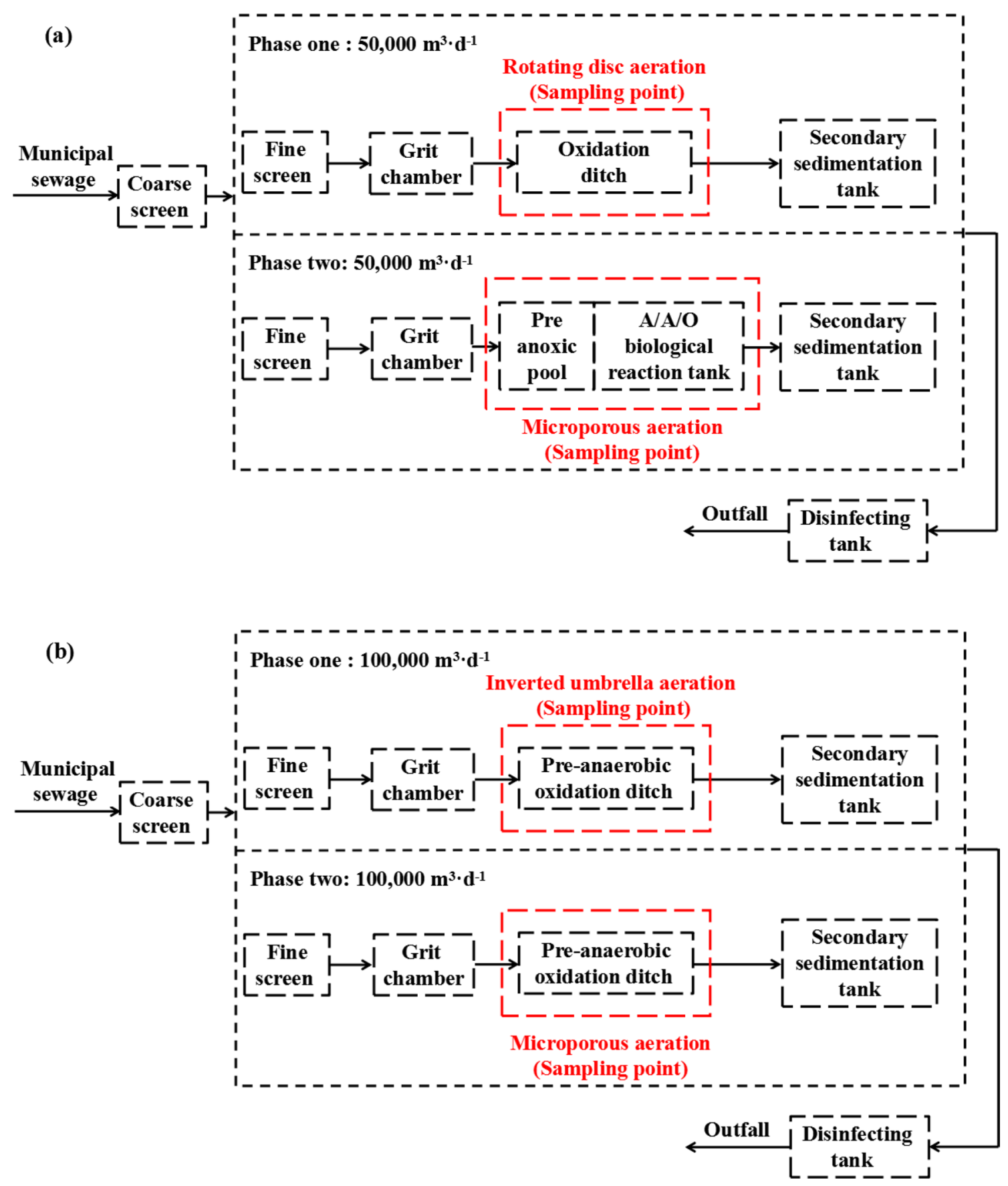

Fig. 1 Schematic diagram of wastewater treatment process in (a) plant A and (b) plant B

Material Table 1. The dissolved oxygen in various aeration tanks is shown in Supplementary Material Table 2.

\section{Sampling procedure}

According to our previous research (Chen et al. 2021), Staphylococcus aureus and gram-negative bacteria bioaerosols samplings were conducted 6 times from November 2019 to January 2020 using a six-stage Andersen impactor with a flow rate of $28.3 \mathrm{~L} \mathrm{~min}^{-1}$ and aerodynamic cut-size diameters of 7.0, 4.7, 3.3, 2.1, 1.1, and $0.65 \mu \mathrm{m}$ (Uhrbrand et al. 2017). The sampling site was at a height of $1.5 \mathrm{~m}$ above the aeration tanks' ground and located in the middle of the aeration tank. The sampling points were established at rotating disc aeration tank and microporous aeration tank in plant $\mathrm{A}$ and inverted umbrella aeration tank and microporous aeration tank in plant B (Fig. 1). Sampling date and time in each sampling point are listed in details in the Supplementary 
Material Table 3. The sampling for Staphylococcus aureus and gram-negative bacteria bioaerosol was carried out for 10 and $20 \mathrm{~min}$, respectively. The plate that used in the Andersen impactor was an egg-yolk mannitol salt agar medium and a Gram-negative bacteria selective medium for Staphylococcus aureus and Gram-negative bacteria bioaerosols, respectively (Qingdao Hope Bio-Technology Co., Ltd., China) (Grzyb and Lenart-Boron 2019; Stiles 1977; Zhang et al. 2018). Three replicates were taken consecutively from each aeration tank.

During the sampling campaign, the temperature (expressed in ${ }^{\circ} \mathrm{C}$ ) and the relative humidity (expressed in percentages) were monitored using a digital thermohygrometer (TASI-622, Suzhou TASI Electronics Co., Ltd., China). According to the manufacturer, the accuracy of the temperature reading were $\pm 2{ }^{\circ} \mathrm{C}$ in the $0-10{ }^{\circ} \mathrm{C}$ range and $\pm 0.5{ }^{\circ} \mathrm{C}$ in the $10-45{ }^{\circ} \mathrm{C}$ range. The accuracy of the humidity reading was $\pm 2.5 \%$. When measuring, the digital thermohygrometer was placed at the same height as the sampler. The illuminance (expressed in $L_{\mathrm{X}}$ ) of solar radiation was determined using a light meter (Tes-1339, Tes Electrical Electronic Corp., China). The light meter was placed on the unshaded ground at sampling sites and the data was recorded. Air quality index (AQI) was a unitless parameter to measure the overall quality of the air on a scale of $0-500$. A low number means good air quality while higher numbers means worse air quality. The hourly AQI was obtained from weather stations closest to the sampling sites. These data are summarized in Supplementary Material Table 4.

\section{Bioaerosol characterization}

All collected samples were transported immediately to the laboratory with a cold box and were incubated at $37{ }^{\circ} \mathrm{C}$ for $24 \mathrm{~h}$ to develop colonies (Bragoszewska and Biedron 2018; Szyłak-Szydłowski et al. 2016). The colonies, which were visible on the plate, were counted by an automatic colonycounting instrument (HICC-B, Wanshen, Hangzhou). The concentration of microbial bioaerosols was calculated by dividing the volume of air sampled from the sum number of colonies on the plate, as shown in Eq. (1). The number of colonies was corrected by positive-hole correction (Andersen 1958; Macher 1989) as follows:

$C=\frac{N_{1}+N_{2}+\ldots+N_{6}}{Q \mathrm{t}} \times 1000$,

where $C$ refers to the bioaerosol concentration and is expressed as $\left(\mathrm{CFU} \mathrm{m}{ }^{-3}\right) . N_{1}-N_{6}$ are the number of colonies on each stage of the six-stage Andersen impactor. $Q$ is the flow rate $\left(28.3 \mathrm{~L} \mathrm{~min}^{-1}\right)$, and $t$ is the sampling time for the microbial bioaerosol (min).
The median, mean, and standard deviation of the experimental data were calculated with outlier samples taken into account. The maximum and minimum values were on behalf of the worst estimate and the optimistic estimate, respectively (Lim et al. 2015; Stellacci et al. 2010). Part of these date have been already contained in our previous research (Chen et al. 2021).

\section{Estimating health risks by QMRA}

The QMRA approach was used to evaluate and quantify the health risks (annual infection risk and disease burden) associated with exposure to microbial bioaerosols (Haas et al. 2014; Parkin 2007). A scenario associated with the health risks after equipping individuals with various grade PPE (KN90, KN95, and KN100) was also analyzed. The QMRA framework included four steps: hazard identification, exposure assessment, dose-response assessment, and risk characterization (Haas et al. 1999; National Academy of Sciences 1983; National Research Council 2009), which are briefly described below.

\section{Hazard identification}

The staffs (field engineer and laboratory technician) employed in WWTPs and temporary entrants (researchers, visitors, and inspectors) were subject to the risk of inhalation of microbial bioaerosol (Myrmel et al. 2015). Reference bioaerosols for this study, including Staphylococcus aureus bioaerosol and Gram-negative bacteria bioaerosol, were selected because they are well-known bioaerosol indicators, and they cause a large proportion of wastewater-associated illnesses (Douwes et al. 2003; Fracchia et al. 2006; Rosenberg Goldstein et al. 2012). In the QMRA calculation process of this study, all pathotypes of Gram-negative bacteria bioaerosol were assumed to be pathogenic E. coli bioaerosol (Shi et al. 2018).

\section{Exposure assessment}

The objective of the exposure assessment was to estimate the dose of microbial bioaerosol to which staffs employed in WWTPs and temporary entrants might be exposed within a day and a year. In the present study, several exposure scenarios were evaluated (Table 1). The exposure dose of microbial bioaerosol was estimated using Eq. (2) (Brooks et al. 2012):

$d=C \times \mathrm{RR} \times \mathrm{IR} \times \mathrm{ET}$,

where $d$ is the exposure dose expressed in pathogens day ${ }^{-1}$, $C$ is the concentration of the microbial bioaerosol detected in bioaerosol samples $\left(\mathrm{CFU} \mathrm{m}{ }^{-3}\right), R R$ is the respiratory intake 
ratio, $I R$ is the inhaled breathing rate ( $\mathrm{m}^{3} /$ day), and $E T$ is the exposure time (h/day).

The parameter respiratory intake ratio was calculated from experimental data. Approximately $74 \%$ of all the bioaerosol particles collected by the Andersen impactor, on average, had a diameter $<4.7 \mu \mathrm{m}$ (stage 3-6) (Supplementary Material Table 5) (Pillai 2007; Szyłak-Szydłowski et al. 2016; Wathes et al. 1988). Hence, it was assumed that the respiratory intake ratio was 0.74 .

\section{Dose-response assessment}

The dose-response model estimated the probability of infection caused by exposure to microbial bioaerosol (Katukiza et al. 2014). The exponential dose-response model, which was used for Staphylococcus aureus bioaerosol, is shown in Eq. (3) (Rose and Haas 1999):

$P_{\text {inf }}=1-e^{-r d}$,

where $P_{\text {inf }}$ is the probability of being infected after daily exposure (per person per day), $d$ is the exposure dose calculated in Eq. (2) (pathogens day ${ }^{-1}$ ), and $\mathrm{r}$ is the model parameter for Staphylococcus aureus bioaerosol infection risk.

For Gram-negative bacteria bioaerosol, the beta-Poisson dose-response model was used to calculate the infection risk, as defined by Eq. (4) (DuPont et al. 1971)

$P_{\mathrm{inf}}=1-(1+d / \beta)^{-\alpha}, \beta=\frac{N_{50}}{2^{\frac{1}{\alpha}}-1}$,

where $\alpha, \beta$, and $N_{50}$ are the best-fit parameters of the model, which represent the pathogenicity of Gram-negative bacteria bioaerosol.

The annual infection risks were calculated on the basis of the theorem of independence using Eq. (5)

$P_{\mathrm{a}(\mathrm{inf})}=1-\left(1-P_{\mathrm{inf}}\right)^{n}$,

where $P_{a(\text { inf })}$ is the probability of being infected after a yearly exposure expressed in per person per year (pppy). $P_{\text {inf }}$ is the probability of being infected after daily exposure (per person per day), and $n$ is the number of days exposed per year (d $\mathrm{a}^{-1}$ ). All parameters related to these models of the QMRA can be found in Supplementary Material Table 6.

\section{Risk characterization}

Risk characterization was carried out on the basis of the information provided from the aforementioned hazard identification, exposure assessment, and dose-response assessment. The health risks, including annual infection risk and disease burden, were estimated for each scenario presented 
in Table 1 and the scenario of field engineers equipped with PPE. The results of health risks were characterized according to the U.S. EPA annual probability of infection benchmark $\left(\leq 10^{-4}\right.$ pppy) and the WHO disease burden benchmark $\left(\leq 10^{-6}\right.$ DALYs pppy $\left.{ }^{-1}\right)$ (U.S. EPA 2005; WHO 2008). The estimation of the disease burden is provided by Eq. (6) (Pasalari et al. 2019)

$\mathrm{DB}=P_{\mathrm{a}(\mathrm{inf})} \times P_{\mathrm{ill} / \mathrm{inf}} \times \mathrm{HB}$,

where DB is the disease burden expressed in DALYs per person per year (DALYs pppy ${ }^{-1}$ ). $P_{a \text { (inf) }}$ is the annual infection risk (pppy), $P_{\mathrm{ill} / \mathrm{inf}}$ is the probability of illness to infection ratio, and $H B$ is the disease burden per case (DALYs per case). These parameters are presented in Supplementary Material Table 6.

\section{Results and discussion}

\section{Bioaerosol concentrations}

The influence of temporal variations of meteorological factors on microbial bioaerosol emissions can be seen in the Supplementary Material Fig. 1. According to the last two times sampling in January 2020, the concentrations of microbial bioaerosols were generally increased with the decrease of illumination while there is no distinct difference between concentrations and other meteorological factors. This was because high illuminance of solar radiation could affect the survival of microbial bioaerosols aerosolized from wastewater and result in partial inactivation (Maier et al. 2000). Meanwhile, several studies have been also revealed that low temperature, high humidity, and low illuminance of solar radiation tended to favor microbial bioaerosols' survival (Hughes 2003; Mohr 2007; Stellacci et al.
2010). The concentrations of microbial bioaerosols were affected by various meteorological factors, but the aeration mode was dominant in this study.

Table 2 shows the concentrations of Gram-negative bacteria bioaerosol and Staphylococcus aureus bioaerosol in the aeration tanks of the two WWTPs. Figure 2 presents the size distribution of two microbial bioaerosols. Part of these date have been showed in our previous research (Chen et al. 2021). The average bioaerosol concentrations in the rotating disc aeration tank were two orders of magnitude higher

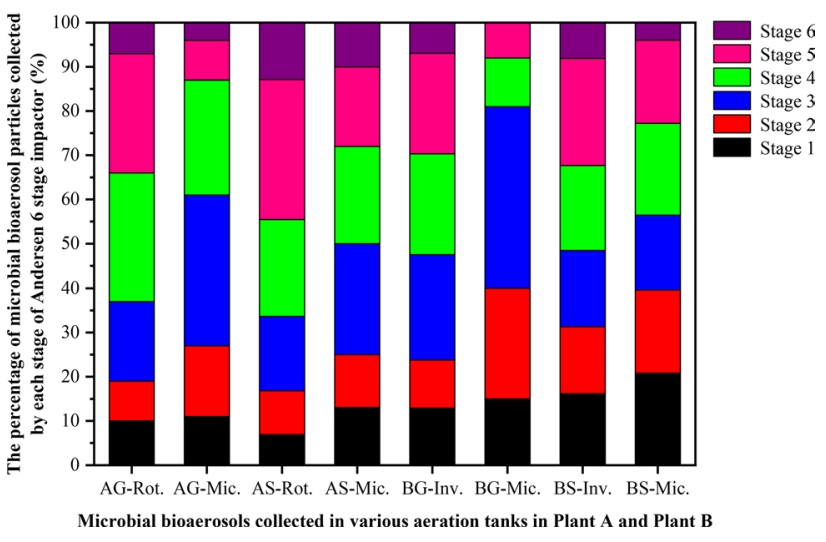

Fig. 2 Size distribution ratio of microbial bioaerosols collected by six-stage Andersen impactor in various aeration tanks of plant A and plant B. AG-Rot. Gram-negative bacteria bioaerosol collected in rotating disc aeration tank in plant A, AG-Mic. Gram-negative bacteria bioaerosol collected in microporous aeration tank in plant A; AS-Rot. Staphylococcus aureus bioaerosol collected in rotating disc aeration tank in plant A, AS-Mic. Staphylococcus aureus bioaerosol collected in microporous aeration tank in plant A, BG-Inv. Gram-negative bacteria bioaerosol collected in inverted umbrella aeration tank in Plant B; BG-Mic. Gram-negative bacteria bioaerosol collected in microporous aeration tank in Plant B, BS-Inv. Staphylococcus aureus bioaerosol collected in inverted umbrella aeration tank in Plant B, BS-Mic. Staphylococcus aureus bioaerosol collected in microporous aeration tank in Plant B

Table 2 Microbial bioaerosol concentrations $\left(\mathrm{CFU} \mathrm{m}{ }^{-3}\right)$ in various sampling sites

\begin{tabular}{|c|c|c|c|c|}
\hline \multirow[t]{2}{*}{ Items } & \multicolumn{2}{|l|}{ Plant A } & \multicolumn{2}{|l|}{ Plant B } \\
\hline & $\begin{array}{l}\text { Rotating disc aeration } \\
\text { tank }\end{array}$ & $\begin{array}{l}\text { Microporous aeration } \\
\text { tank }\end{array}$ & $\begin{array}{l}\text { Inverted umbrella } \\
\text { aeration tank }\end{array}$ & $\begin{array}{l}\text { Microporous aeration } \\
\text { tank }\end{array}$ \\
\hline \multicolumn{5}{|c|}{ Gram-negative bacteria bioaerosol } \\
\hline Max & 189.03 & 17.77 & 122.33 & 24.32 \\
\hline Min & 21.88 & 3.54 & 32.59 & 1.77 \\
\hline Median & 113.31 & 6.50 & 59.38 & 5.76 \\
\hline Mean \pm SD & $114.60 \pm 63.02$ & $8.37 \pm 4.76$ & $67.55 \pm 32.16$ & $8.19 \pm 7.61$ \\
\hline \multicolumn{5}{|c|}{ Staphylococcus aureus bioaerosol } \\
\hline Max & $15,760.04$ & 1307.64 & 593.34 & 332.71 \\
\hline Min & 4560.25 & 58.01 & 124.57 & 0 \\
\hline Median & $11,614.54$ & 189.27 & 200.43 & 77.80 \\
\hline Mean \pm SD & $11,103.13 \pm 3362.95$ & $331.83 \pm 332.84$ & $257.49 \pm 153.74$ & $101.71 \pm 107.91$ \\
\hline
\end{tabular}


than those in the microporous aeration tank in plant $\mathrm{A}$. In plant $\mathrm{B}$, lower bioaerosol concentrations were still detected in the microporous aeration tank rather than the inverted umbrella aeration tank. Previous works had reported similar results, in which the mechanical agitation of wastewater using horizontal rotors (e.g., rotating disc aeration mode) or surface turbines (e.g., inverted umbrella aeration mode) raised higher concentrations of bioaerosol emissions than that of diffuser aerators (e.g., blast microporous aeration mode) (Brandi et al. 2000; Sanchez-Monedero et al. 2008). Therefore, mechanical agitation (rotating disc aeration mode and inverted umbrella aeration modes) seems to generate more bioaerosol emissions than the blast aeration mode.

In fact, these results were unsurprising and expected, as the bursting of bubbles at the wastewater liquid surface had been well recognized as an important generation mechanism for bioaerosol emissions from the blast aeration mode (Resch et al. 1992). Air was injected into the bottom of the aeration tank by a microporous aeration device, which transferred oxygen from air into wastewater as it rose upward. Remaining at the wastewater liquid surface, the bubble film became thin and then gently burst into minor droplets that enclosed microbial suspensions (Blanchard et al. 1975). Finally, these droplets evaporated to form microbial bioaerosol particles (Fannin et al. 1985). Nevertheless, mechanical agitation caused turbulence and fierce splashing that might lead to the generation of droplets, which resulted in a large amount of microorganisms splashing out and releasing into the air (Korzeniewska 2011). Evidently, the blast aeration mode induced only minor turbulence to wastewater rather than in the violent mechanical aeration agitation to emit microbial bioaerosol (Korzeniewska et al. 2007). Referring to the blast aeration mode (the two microporous aeration tanks), the concentrations of microbial bioaerosols in plant A were generally one to two orders of magnitude higher than those in Plant B. This variation was related to the different water quality (Supplementary Material Table 1) and dissolved oxygen (Supplementary Material Table 2) of the two WWTPs (Piqueras et al. 2016).

According to the Polish Standard, the microbial bioaerosol emissions in all aeration tanks were generally regarded as safe (Polska Norma PN-89 Z-04111 02). The exception was the Staphylococcus aureus bioaerosol emissions in the rotating disc aeration tank in plant $\mathrm{A}$, which was considered as heavily contaminated on the basis of the Polish Standard (Polska Norma PN-89 Z-04111 02), was over the maximum allowable concentration of total bacterial bioaerosol by Korean standards (Ministry of Environment, Republic of Korea 2010) and the National Institute of Occupational Safety and Health standards (Vilavert et al. 2009). The concentration also exceeded the Swiss occupational exposure limits (OELs) (Oppliger et al. 2005). However, the abovementioned standards or OELs may not have scientific justification because bioaerosols are complex mixtures of microbial particles (ACGIH 1989; Vilavert et al. 2009). These standards and OELs are usually founded on simple baseline bioaerosol concentrations rather than dose-response relationships of health risk assessment, thus neglecting the effects of such concentrations on human health (Kim et al. 2018). Therefore, no internationally accepted standards or OELs for microbial bioaerosol emission have been formulated (Turner et al. 2008).

\section{Annual infection risks}

The annual infection risks of Gram-negative bacteria bioaerosol and Staphylococcus aureus bioaerosol referring to various exposure scenarios in the two WWTPs are presented in Table 3. The infection risks of females were always smaller than those of males for the grow-ups age group. This difference was caused by the huge inconsistency of the breathing rate between the genders (Supplementary Material Table 6). In the elderly age group, the infection risks of microbial bioaerosol showed no significant differences between the two genders. This comparison signified that the inhaled breathing rate of elderly males and females were nearly the same (Supplementary Material Table 6). The correlation between the inhaled breathing rate and the infection risks of microbial bioaerosols was consistent with other studies. As described by Shi et al. (2018), the infection risks are commonly expressed on the basis of the dose of exposure to microbial bioaerosol concentrations, which is highly affected by the inhaled breathing rate (Brooks et al. 2012).

The infection risks of Gram-negative bacteria bioaerosol for visitors and inspectors were slightly one order of magnitude higher or even on the same order of magnitude as the U.S. EPA annual infection benchmark $\left(\leq 10^{-4}\right.$ pppy). However, for researchers, the infection risks were higher than the benchmark by two orders of magnitude because the exposure time for researchers was much longer than that for visitors and inspectors (Table 1). Moreover, the exposure time and the infection risks had a significantly positive relationship (Blanky et al. 2017). Notably, under the optimistic estimate (i.e., for the min value of the annual probability of infection), elderly female inspectors could still be deemed acceptable because these inspectors' infection risks satisfied the benchmark. In view of the uncertainty of the estimation, the worst case estimate was taken into account through the risk assessment, which was considered overly conservative and impractical (Shi et al. 2018; Stellacci et al. 2010). In contrast, conducting the risk assessment under an optimistic estimate would more effectively inform stakeholders of the range of the annual probability of infection that microbial bioaerosols might cause.

However, the infection risks for all staffs were generally two orders of magnitude over the benchmark. Therefore, 


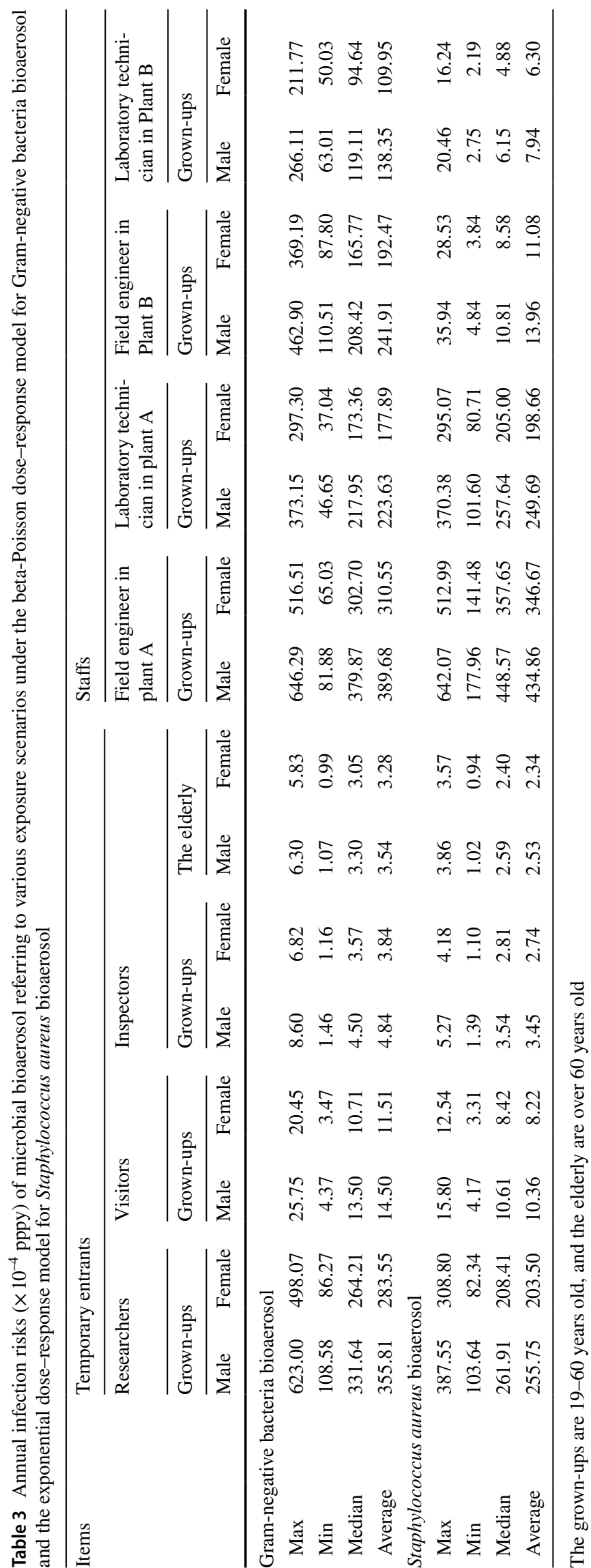


sewage workers were at a higher risk metric of developing a large variety of work-related infection risks compared with temporary entrants (Masclaux et al. 2014). Several works had reported similar results that sewage workers severely suffered a markedly higher prevalence than others of a particular illness called "sewage worker's syndrome" (Clark 1987; Fannin et al. 1985). Besides, it is worth noting that although the microbial bioaerosol emissions in all aeration tanks were largely regarded as safe according to existing standards (Sect. 3.1), their infection risks were still unacceptable here.

The infection risks of Staphylococcus aureus bioaerosol for visitors and inspectors were generally on the same order of magnitude as the U.S. EPA benchmark (except the grownup male visitors). However, for researchers, the infection risks were much higher than the benchmark by approximately two orders of magnitude. The researchers' exposure time was much longer than the other two temporary entrants (Table 1). The infection risks for all staffs in plant A were two orders of magnitude higher than the benchmark. However for staffs in Plant B, the infection risks were marginally one order of magnitude higher or even on the same order of magnitude as the benchmark. This result could be attributed to the high concentrations of Staphylococcus aureus bioaerosol in plant A (Table 2). For all exposure scenarios, even under the optimistic estimate, the infection risks of Staphylococcus aureus bioaerosol were still generally over the benchmark (except the elderly female inspectors). Thus, the Staphylococcus aureus bioaerosol generated during wastewater treatment posed a considerable infection health risk to the exposure of temporary entrants and staff.

\section{Disease burden}

The disease burden of Gram-negative bacteria bioaerosol and Staphylococcus aureus bioaerosol for temporary entrants and staff in the two WWTPs are listed in Table 4. Referring to the WHO disease burden benchmark $\left(\leq 10^{-6}\right.$ DALYs pppy $\left.{ }^{-1}\right)$, the results of the disease burden of Gramnegative bacteria bioaerosol were nearly the same as the estimation of the annual infection risks (Table 3 ). The exception was that the elderly female inspectors still exceeded the benchmark even under the optimistic estimate (i.e., for the min value of the disease burden). This trend was likely due to the relatively high pathogenicity of Gram-negative bacteria bioaerosol (Jahne et al. 2015).

The disease burdens of Staphylococcus aureus bioaerosol for temporary entrant researchers and visitors both exceeded the benchmark. However, the optimistic estimate for female grown-up visitors, indicated that their health risk could still be considered acceptable, as their disease burdens satisfied the benchmark. This level of acceptability was due to the slow inhaled breathing rate of female grown-up
(Supplementary Material Table 6) and the low concentration of Staphylococcus aureus bioaerosol under the optimistic estimate (i.e., considering the min value of Staphylococcus aureus bioaerosol concentrations in various sampling sites) (Table 2). In contrast, the disease burdens of the temporary entrant inspectors were over the benchmark under the worst estimate (i.e., for the max value of the disease burden), but their disease burdens generally satisfied the benchmark. This result entailed that a potential disease health burden risk for inspectors was non negligible. The exception was for the female elderly inspectors whose disease health burdens always fulfilled the benchmark under all estimates. This outcome could be explained by the theory that slower inhaled breathing rate (Supplementary Material Table 6) and shorter annual exposure time (Table 1) might result in a lower health risk for female elderly inspectors (Blanky et al. 2017).

As for the staffs, the disease burdens of the two microbial bioaerosols in all exposure scenarios were generally above the benchmark. Notably, under the optimistic estimate for the laboratory technician in Plant B, the disease burdens of Staphylococcus aureus bioaerosol could satisfy the benchmark. The Staphylococcus aureus bioaerosol in Plant B had a lower concentration under the optimistic estimate (i.e., considering the min value of Staphylococcus aureus bioaerosol concentrations in various sampling sites) (Table 2). In conclusion, these results presented a high disease health risk burden for staffs, which could not be ignored. Sewage workers exposed to microbial bioaerosols for a long time were at risk. Thus, a significant association between exposure to microbial bioaerosol emissions and health was at stake (Cyprowski and Krajewski 2003; Heng 1994; Patentalakis et al. 2008).

In addition, the disease burdens of microbial bioaerosol showed no significant differences between the grow-ups age group and the elderly age group. When calculating disease burdens, the unique characteristics of different age groups on morbidity and mortality were not taken into account, which was affected by the lack of local surveillance data. Thus, this calculation might not best characterize the true impacts of illnesses related to microbial bioaerosols. In fact, the disease surveillance data were often regionally bounded as a consequence of the differences in medical resources and living habits in different regions (Lim et al. 2015; Shi et al. 2018). Thus, disease surveillance databases, which are based on surveillance data from various regions of the world, are needed for a more accurate and more reliable health risk assessment (Shi et al. 2018).

\section{Health risks for field engineers equipped with personal protection equipment}

Tables 5 and 6 show the annual infection risks and disease burdens of field engineers equipped with various grade 


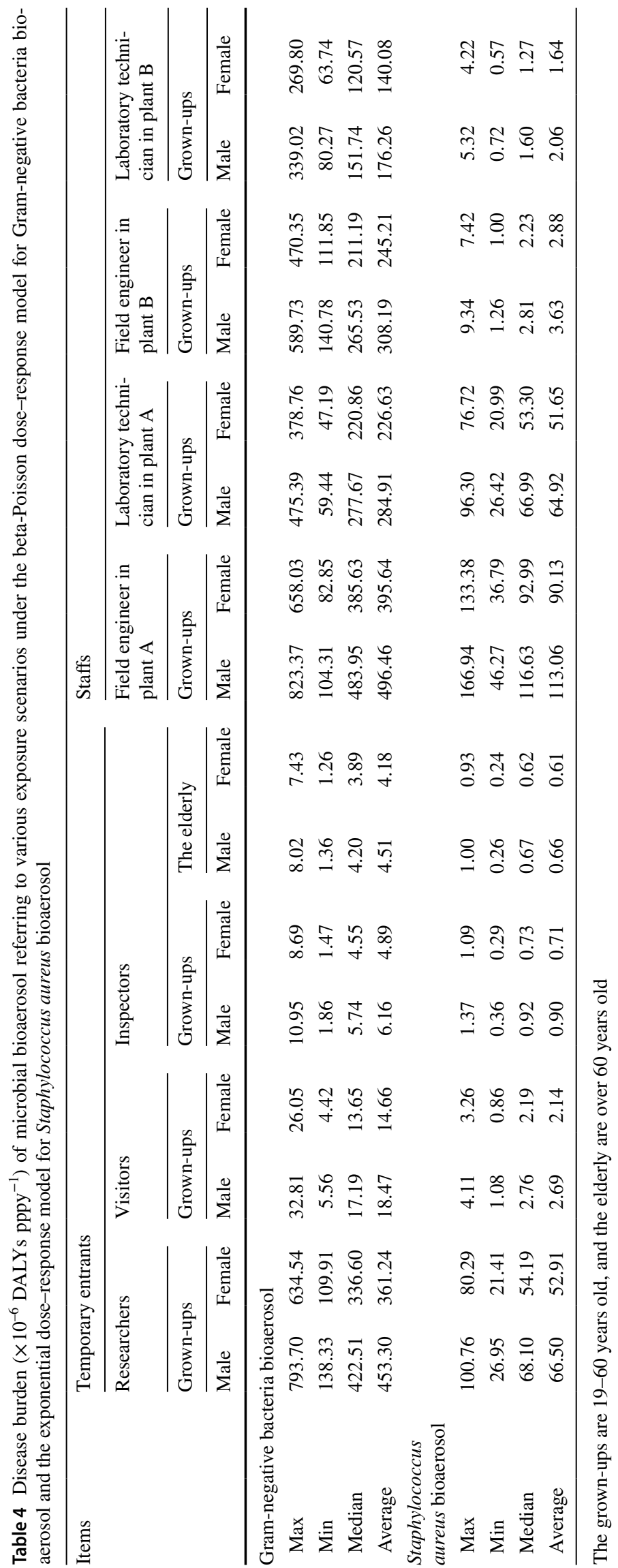




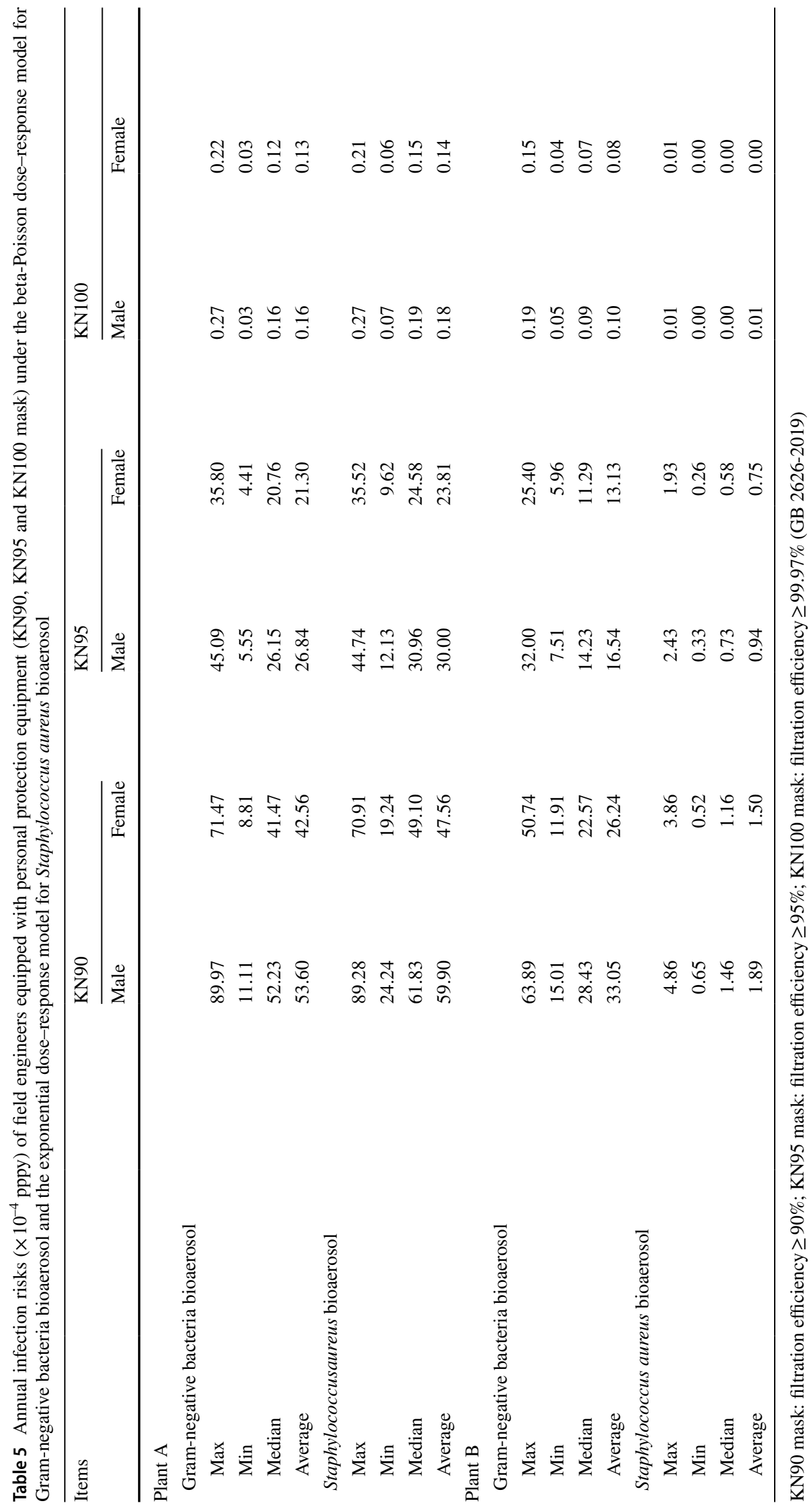




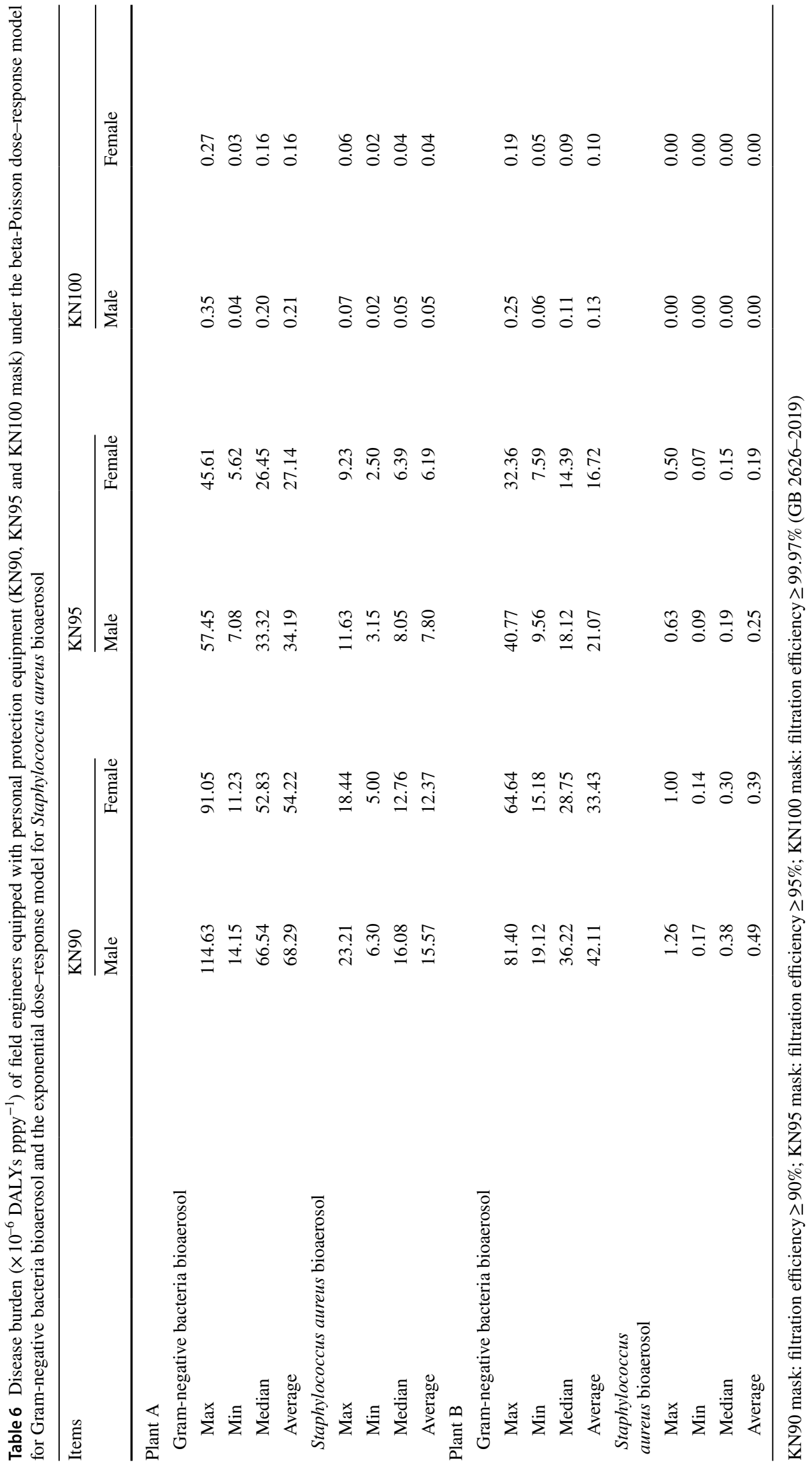


PPE (KN90, KN95 and KN100 mask) in the two WWTPs, respectively. The results of the disease burden were similar to the estimation of the infection risks. The health risks (annual infection risk and disease burden) for field engineers were significantly lower than those without PPE. Masks can block most of the microbial bioaerosols due to its good filtration efficiency, thus effectively protecting its wearers (GB 2626-2019; Liu and Zhao 2020).

When field engineers were equipped with KN90 masks, the health risks were generally one order of magnitude higher than the WHO and U.S. EPA benchmarks. The exception was the health risks of Staphylococcus aureus bioaerosol in Plant B. The disease health burdens satisfied the WHO benchmark in general but not for the worst estimate (i.e., for the max value of the disease burden) (Table 6). In addition, the annual health infection risks complied with the U.S. EPA benchmark under the optimistic estimate (i.e., for the min value of the annual infection risks) (Table 5). This outcome was mainly due to the lower concentration of Staphylococcus aureus in Plant B (Table 2). Compared with KN90 masks, the health risks for field engineers equipped with KN95 masks were reduced but still exceeded the benchmarks. The exception was that the health risks of Staphylococcus aureus bioaerosol in Plant B generally satisfied the benchmarks but exceeded the U.S. EPA benchmark under the worst estimate (Table 5). The worst estimate of Staphylococcus aureus bioaerosol in Plant B had a higher concentration (i.e., considering the max value of Staphylococcus aureus bioaerosol concentrations in various sampling sites) (Table 2). These results indicated that KN90 and KN95 masks could not fully protect field engineers from microbial bioaerosols, which still posed unacceptable risks to them. However, the health risks for field engineers equipped with KN100 masks were clearly acceptable in relation to the U.S. EPA and WHO benchmarks, and the result sometimes even reached zero when two decimal places were reserved. Therefore, equipping workers with KN100 masks is recommended to reduce health risks related to sewage workers effectively. However, absolute safety is unattainable according to field engineers (Haas 2015). Completely eliminating the health risks inherent to field engineers in wastewater treatment is impossible, and the best efficient prevention measures must be implemented to minimize the generation of microbial bioaerosols exposure dose at the workplace (Teixeira et al. 2013).

\section{Uncertainties during QMRA process}

Given that not all individuals in the exposure population infected with microbial bioaerosol ended up exhibiting symptoms and became ill, the burden of disease could measure the impact of particular health conditions, not only focusing on annual infection risks (Blanky et al. 2017). Simple yes-or-no judgments by only one commonly adopted benchmark is an oversimplification of the assessment (De Gisi et al. 2016). However, the two health risk benchmarks (the U.S. EPA annual infection benchmark and the WHO disease burden benchmark) should be used as complements rather than in opposition (Lim et al. 2015).

The WHO disease burden benchmark and the U.S. EPA benchmark, which were originally and primarily established for the assessment of safe drinking water, might not be very suitable for the health risk assessment on bioaerosol pollution (Mara 2011; Mara and Sleigh 2010). Thus, such benchmarks should calculate the risk assessment more accurately by taking the optimistic estimate and the worst estimate into consideration (Shi et al. 2018). These shortcomings also implied the need for incorporating updated science into risk assessment, which could be used to revise the current health risk benchmarks (Lim et al. 2015).

Moreover, dose-response models used for estimating infection risks might be the most important source of uncertainties during the QMRA process (Lim et al. 2015). Although the dose-response models of different bioaerosol pathotypes were not exactly the same due to different infection or illness mechanisms, dose-response models had not been established for all scenarios (Graham et al. 1983; June et al. 1953; Levine et al. 1977). Therefore, these variations would overestimate or underestimate the health risk. Another reason for the uncertainty was that dose-response models to date usually only focus on single pathogen bioaerosols (Haas, 2015). However, in realistic exposure scenarios in WWTPs, concomitant exposure to multiple bioaerosol pathogens are possible (Aksoy et al. 2007; Bopp et al. 2003; Gallayet al. 2006). Consequently, further improvements on data collection and model refinement are necessary to restrict the uncertainties associated with the health risk outcomes (Lim et al. 2015).

The traditional QMRA approach still contains many uncertainties and variability that are not mentioned and considered above. Some statistical approaches, such as the Monte Carlo simulation approach, can be used to take into account the uncertainties in the process of QMRA (Nauta 2000). Meanwhile, the modeling approach can be improved by considering the variability and uncertainties of different parameters involved in the QMRA model (Chen et al. 2021). The approach used most frequently is to apply Bayesian inference to a QMRA model (Courault et al. 2017; Rigaux et al. 2013).

\section{Conclusion}

Although the results of the bioaerosols concentrations were generally regarded as safe compared with published standards and OELs except for the concentration of Staphylococcus aureus bioaerosol in the rotating disc 
aeration tank in plant A, these bioaerosols' occupational health risks were still unacceptable. Referring to the disease burdens of inspectors, no significant differences were observed between the grow-ups age group and the elderly age group. The health risks of females were always smaller than those of males for the grown-ups age group due to the huge inconsistency of the inhaled breathing rate of the genders. Staffs who had been exposed to bioaerosols for a long time had higher health risks compared with temporary entrants. The health risks in all exposure scenarios were generally above the WHO and U.S. EPA benchmarks except for those of the female elderly inspectors exposed to Staphylococcus aureus bioaerosol. These results showed that bioaerosols posed considerable infection health risks to exposed temporary entrants and staffs in WWTPs. The risk assessment for field engineers equipped with PPE rendered a low health risk, which revealed that PPE could effectively protect the wearers and reduce the occupational health risks. Moreover, a higher filtration efficiency of PPE increases the protective effect of the equipment on the wearers. The present research provided novel data and enriched the knowledge of microbial bioaerosols emissions' health risks from various aeration modes in WWTPs. Furthermore, it significantly aided in advancing the understanding of human health risks in various exposure scenarios associated with the annual infection risk and disease burden. Then, management decisions can be implemented by authorities on the basis of the results of the QMRA for field engineers equipped with PPE to abate the related occupational health risks.

Supplementary Information The online version contains supplementary material available at https://doi.org/10.1007/s00420-021-01663-5.

Acknowledgements This study was sponsored by the National Natural Science Foundation of China (51608497), the Fundamental Research Funds for the Central Universities, China University of Geosciences (Wuhan) (CUGL170409, CUG170103, CUGGC07), and the Program of Geological Processes Resources and Environment in the Yangtze Basin (CUGCJ1702).

Author contributions Conceptualization: CY, YL; methodology: CY, YL; formal analysis and investigation: CY, YL, JW; writing-original draft preparation: CY, YL, JW; writing-review and editing: CY, YL, JW; funding acquisition: CY; resources: CY; supervision: CY.

Funding We declare that the sources of funding for this research include the National Natural Science Foundation of China, the Fundamental Research Funds for the Central Universities, China University of Geosciences (Wuhan), and the Program of Geological Processes Resources and Environment in the Yangtze Basin. The funding bodies only provide financial support in the design of the study and collection, analysis, and interpretation of data and in writing the manuscript.

Availability of data and material All data generated or analyzed during this research are included in this published article and its supplementary information files.

\section{Compliance with ethical standards}

Conflict of interests The authors all declare that they have no conflict of interest.

\section{References}

ACGIH (1989) Guidelines for the assessment of bioaerosols in indoor environment. In: American conference of governmental industrial hygienists, Cincinnati, Ohio

Abia ALK, Ubomba-Jaswa E, Genthe B, Momba MNB (2016) Quantitative microbial risk assessment (QMRA) shows increased public health risk associated with exposure to river water under conditions of riverbed sediment resuspension. Sci Total Environ 566-567:1143-1151

Aksoy U, Akisu C, Sahin S, Usluca S, Yalcin G, Kuralay F, Oral A (2007) First reported waterborne outbreak of cryptosporidiosis with Cyclospora co-infection in Turkey. Euro Surveill 12(2):E070215.4

Andersen AA (1958) New sampler for the collection, sizing, and enumeration of viable airborne particles. J Bacteriol 76(5):471-484

Ariya PA, Amyot M (2004) New directions: the role of bioaerosols in atmospheric chemistry and physics. Atmos Environ 38(8):1231-1232

Asadi S, Ni B, Wexler AS, Ristenpart WD (2020) The coronavirus pandemic and aerosols: does COVID-19 transmit via expiratory particles? Aerosol Sci Tech 54(6):635-638

Blanchard DC, Syzdek LD (1975) Electrostatic collection of jet and film drops. Limnol Oceanogr 20(5):762-774

Blanky M, Sharaby Y, Rodríguez-Martínez S, Halpern M, Friedler E (2017) Greywater reuse-assessment of the health risk induced by Legionella pneumophila. Water Res 125(15):410-417

Bopp DJ, Sauders BD, Waring AL, Ackelsberg J, Dumas N, BraunHowland E, Dziewulski D, Wallace BJ, Kelly M, Halse T, Musser KA, Smith PF, Morse DL, Limberger RJ (2003) Detection, isolation, and molecular subtyping of Escherichia coli O157:H7 and Campylobacter jejuni associated with a large waterborne outbreak. J Clin Microbiol 41(1):174-180

Bragoszewska E, Biedron I (2018) Indoor air quality and potential health risk impacts of exposure to antibiotic resistant bacteria in an office rooms in Southern Poland. Int J Environ Res Public Health 15(11):2604

Brandi G, Sisti M, Amagliani G (2000) Evaluation of the environmental impact of microbial aerosols generated by wastewater treatment plants utilizing different aeration systems. J Appl Microbiol 88(5):845-852

Brooks JP, Gerba CP, Pepper IL (2004) Aerosol emission, fate, and transport from municipal and animal wastes. J Residuals Sci Technol 1(1):13-25

Brooks JP, McLaughlin MR, Gerba CP, Pepper IL (2012) Land application of manure and class B biosolids: an occupational and public quantitative microbial risk assessment. J Environ Qual 41(6):2009-2023

Carducci A, Donzelli G, Cioni L, Federigi I, Lombardi R, Verani M (2018) Quantitative microbial risk assessment for workers exposed to bioaerosol in wastewater treatment plants aimed at the choice and setup of safety measures. Int $\mathbf{J}$ Environ Res Public Health 15(7):1490

Carducci A, Morici P, Pizzi R, Battistini R, Rovini E, Verani M (2008) Study of the viral removal efficiency in an urban wastewater treatment plant. Water Sci Technol 58(4):893-897 
Carducci A, Tozzi E, Rubulotta E, Casini B, Cantiani L, Rovini E, Muscillo M, Pacini R (2000) Assessing airborne biological hazard from urban wastewater treatment. Water Res 34(4):1173-1178

Chen Y, Yan C, Yang Y, Ma J (2021) Quantitative microbial risk assessment and sensitivity analysis for workers exposed to pathogenic bacterial bioaerosols under various aeration modes in two wastewater treatment plants. Sci Total Environ 755(2):142615

Clark CS (1987) Potential and actual biological related health risks of wastewater industry employment. J Water Pollut Control Fed 59(12):999-1008

Codex Alimentarius Commission (1999) Principles and guidelines for the conduct of microbiological risk assessment. CAC/ GL-30. Available online: http://www.fao.org/docs/eims/ upload/215254/CAC_GL30.pdf

Courault D, Albert I, Perelle S, Fraisse A, Renault P, Salemkour A, Amato P (2017) Assessment and risk modeling of airborne enteric viruses emitted from wastewater reused for irrigation. Sci Total Environ 592:512-526

Cyprowski M, Krajewski JA (2003) Harmful agents in municipal wastewater treatment plants. Med Pr 54:73-80

Douwes J, Thorne P, Pearce N, Heederik D (2003) Bioaerosol health effects and exposure assessment: progress and prospects. Ann Occup Hyg 47(3):187-200

Dowd SE, Maier RM (2000) Aeromicrobiology. In: Maier RM, Pepper IL, Gerba CP (eds) Environmental microbiology. Academic Press, Canada, pp 91-122

DuPont HL, Formal SB, Hornick RB, Snyder MJ, Libonati JP, Sheahan DG, Kalas JP (1971) Pathogenesis of Escherichia coli diarrhea. N Engl J Med 285(1):1-9

EPA S (2005) Occurrence and exposure assessment for the final long term 2 enhanced surface water treatment rule. EPA 815-R-06002. United States Environmental Protection Agency, Office of Water, Washington, DC

EPA S (2007) Thesaurus of terms used in microbiological risk assessment. Office of Science and Technology policy, Washington, DC

Eduard W, Heederik D, Duchaine C, Green BJ (2012) Bioaerosol exposure assessment in the workplace: the past, present and recent advances. J Environ Monit 14(2):334-339

Fannin KF, Vana SC, Jakubowski W (1985) Effect of an activated sludge wastewater treatment plant on ambient air densities of aerosols containing bacteria and viruses. Appl Environ Microb 49(5):1191-1196

Fathi S, Hajizadeh Y, Nikaeen M, Gorbani M (2017) Assessment of microbial aerosol emissions in an urban wastewater treatment plant operated with activated sludge process. Aerobiologia 33(4):507-515

Fracchia L, Pietronave S, Rinaldi M, Giovanna MM (2006) Siterelated airborne biological hazard and seasonal variations in two wastewater treatment plants. Water Res 40(10):1985-1994

GB 2626-2019. Respiratory protection-non-powered air-purifying particle respirator. ICS: 13.340 .30 C73. Standardization Administration of China (SAC)

Gallay A, De VH, Cournot M, Ladeuil B, Hemery C, Castor C, Bon F, Mégraud F, Le CP, Desenclos JC, The Outbreak Investigation Team (2006) A large multi-pathogen waterborne community outbreak linked to faecal contamination of a groundwater system, France, 2000. Clin Microbiol Infect 12:561-570

De Gisi S, Casella P, Notarnicola M, Farina R (2016) Grey water in buildings: a mini-review of guidelines, technologies and case studies. Civ Eng Environ Syst 33(1):35-54

Glassmeyer ST, Furlong ET, Kolpin DW, Cahill JD, Zaugg SD, Werner SL, Meyer MT, Kryak DD (2005) Transport of chemical and microbial compounds from known wastewater discharges: potential for use as indicators of human fecal contamination. Environ Sci Technol 39(14):5157-5169

Graham DY, Estes MK, Gentry LO (1983) Double-blind comparison of bismuth subsalicylate and placebo in the prevention and treatment of enterotoxigenic Escherichia coli-induced diarrhea in volunteers. Gastroenterology 85(5):1017-1022

Grinshpun SA, Clark JM (2005) Measurement and characterization of bioaerosols. J Aerosol Sci 36(5-6):553-555

Grzyb J, Lenart-Boron A (2019) Bacterial bioaerosol concentration and size distribution in the selected animal premises in a zoological garden. Aerobiologia 35(2):253-268

Haas CN (2015) Microbial dose response modeling: past, present, and future. Environ Sci Technol 49(3):1245-1259

Haas CN, Rose JB, Gerba CP (1999) Quantitative microbial risk assessment, 1 st edn. Wiley, USA

Haas CN, Rose JB, Gerba CP (2014) Quantitative microbial risk assessment. 2nd edn. Quantitative microbial risk assessment

Hao XY, Li FD, Lv Q, Xu YF, Han YL, Gao H (2019) Establishment of BALB/C mouse models of influenza A H1N1 aerosol inhalation. J Med Virol 91(11):1918-1929

Heederik D, Mutius EV (2012) Does diversity of environmental microbial exposure matter for the occurrence of allergy and asthma? J Allergy Clin Immunol 130(1):44-50

Heng BH (1994) Prevalence of hepatitis A virus among sewage workers in Singapore. Epidemiol Infect 113:121-128

Hickey JLS, Parker CR (1975) Health significance of airborne microorganisms from wastewater treatment processes. Part II: health significance and alternatives from action. Journal WPCF 47(12):2759-2773

Hughes KA (2003) Aerial dispersal and survival of sewage-derived faecal coliforms in Antarctica. Atmos Environ 37:3147-3155

Jahne MA, Rogers SW, Holsen TM, Grimberg SJ (2015) Quantitative microbial risk assessment of bioaerosols from a manure application site. Aerobiologia 31(1):73-87

June R, Febguson W, Wobfel M (1953) Experiments in feeding adult volunteers with Escherichia coli 55, B5, a coliform organism associated with infant diarrhea. Amer J Hygie 57(2):222-236

Karra S, Katsivela E (2007) Microorganisms in bioaerosol emissions from wastewater treatment plants during summer at a Mediterranean site. Water Res 41(6):1355-1365

Katukiza AY, Ronteltap M, van der Steen P, Foppen JWA, Lens PNL (2014) Quantification of microbial risks to human health caused by waterborne viruses and bacteria in an urban slum. J Appl Microbiol 116(2):447-463

Kim KH, Kabir E, Jahan SA (2018) Airborne bioaerosols and their impact on human health. J Environ Sci 67(5):23-35

Konda A, Prakash A, Moss GA, Schmoldt M, Grant GD, Guha S (2020) Aerosol filtration efficiency of common fabrics used in respiratory cloth masks. ACS Nano 14(5):6339-6347

Korzeniewska E (2011) Emission of bacteria and fungi in the air from wastewater treatment plants-a review. Front biosci (Schol ed) 3:393-407

Korzeniewska E, Filipkowska Z, Gotkowska-Płachta A (2007) Municipial wastewater treatment plant as a source of Enterobacteriaceae bacteria in the air. Ochrona Środowiska i Zasobów Naturalnych IOŚ 32:178-183

Levine MM, Caplan ES, Waterman D, Cash RA, Hornick RB, Snyder MJ (1977) Diarrhea caused by Escherichia coli that produce only heat-stable enterotoxin. Infect Immun 17(1):78-82

Lim KY, Hamilton AJ, Jiang SC (2015) Assessment of public health risk associated with viral contamination in harvested urban stormwater for domestic applications. Sci Total Environ 523(1):95-108 
Liu Y, Zhao B (2020) Size-dependent filtration efficiencies of face masks and respirators for removing SARS-CoV-2-laden aerosols. Infect Cont Hosp Ep 1-2

MOHURD (2020) 2018 Statistical Yearbook on Urban and Rural Construction. Ministry of Housing and Urban-Rural Development of the People's Republic of China. Available online: http:// www.mohurd.gov.cn/xytj/tjzljsxytjgb/index.html

Macher JM (1989) Positive hole correction of multiple jet impactors for collecting viable microorganism. Am Ind Hyg Assoc 50(11):561-568

Maier RM, Pepper IL, Gerba CP (2000) Environmental microbiology. Academic Press, San Diego, CA

Mara D (2011) Water-and wastewater-related disease and infection risks: what is an appropriate value for the maximum tolerable additional burden of disease? J Water Health 9(2):217-224

Mara D, Sleigh A (2010) Estimation of norovirus infection risks to consumers of wastewater-irrigated food crops eaten raw. J Water Health 8(1):39-43

Masclaux FG, Hotz P, Gashi D, Savova-Bianchi D, Oppliger A (2014) Assessment of airborne virus contamination in wastewater treatment plants. Environ Res 133:260-265

Ministry of Environment, Republic of Korea (2010) Available online: www.me.go.kr, http://eng.me.go.kr/content.do?method=move.

Moazeni M, Nikaeen M, Hadi M, Moghim S, Mouhebat L, Hatamzadeh M, Hassanzadeh A (2017) Estimation of health risks caused by exposure to enteroviruses from agricultural application of wastewater effluents. Water Res 125:104-113

Mohr AJ (2007) Fate and transport of microorganisms in air. In: Hurst CJ, Crawford RL, Garland JL, Lipson DA, Mills AL, Stetzenbach LD (eds) Manual for environmental microbiology. ASM Press, Washington, pp 961-971

Myrmel M, Lange H, Rimstad E (2015) A 1-year quantitative survey of noro-, adeno-, human boca-, and hepatitis $\mathrm{E}$ viruses in raw and secondarily treated sewage from two plants in Norway. Food Environ Virol 7(3):213-223

National Academy of Sciences (1983) Risk assessment in the Federal Government: managing the process. National Academy Press, Washington, DC

National Research Council (2009) Science and decisions: advancing risk assessment. National Academies Press, Washington, DC

Nauta MJ (2000) Separation of uncertainty and variability in quantitative microbial risk assessment models. Int J Food Microbiol 57:9-18

Nethercott JR, Holness DL (1988) Health-status of a group of sewagetreatment workers in Toronto, Canada. Am Ind Hyg Assoc J 49:346-350

Niazi S, Hassanvand MS, Mahvi AH, Nabizadeh R, Alimohammadi M, Nabavi S, Faridi S, Dehghani A, Hoseini M, Moradi-Joo M, Mokamel A, Kashani H, Yarali N, Yunesian M (2015) Assessment of bioaerosol contamination (bacteria and fungi) in the largest urban wastewater treatment plant in the Middle East. Environ Sci Pollut Res 22(20):16014-16021

Oppliger A, Hilfiker S, Duc TV (2005) Influence of seasons and sampling strategy on assessment of bioaerosols in sewage treatment plants in Switzerland. Ann occup Hyg 49(5):393-400

Orsini M, Laurenti P, Boninti F, Arzani D, Ianni A, Romano-Spica V (2002) A molecular typing approach for evaluating bioaerosol exposure in wastewater treatment plant workers. Water Res 36(5):1375-1378

Parkin RT (2007) Microbial risk assessment. In: Robson MG, Toscano WA (eds) Risk assessment for environmental health. Jossey-Bass, San Francisco, CA, pp 285-313

Pasalari H, Ataei-Pirkooh A, Aminikhah M, Jafari AJ, Farzadkia M (2019) Assessment of airborne enteric viruses emitted from wastewater treatment plant: atmospheric dispersion model, quantitative microbial risk assessment, disease burden. Environ Pollut 253:464-473

Pascual L, Perez-Luz S, AdelaYanez M, Santamaria A, Gibert K, Salgot M, Apraiz D, Catalan V (2003) Bioaerosol emission from wastewater treatment plants. Aerobiologia 19:261-270

Patentalakis N, Pantidou A, Kalogerakis N (2008) Determination of Enterobacteriae in air and wastewater samples from a wastewater treatment plant by epi-fluorescence microscopy. Water Air Soil Poll: Focus 8(1): 107-115

Pillai SD (2007) Bioaerosols from land applied biosolids: issues and needs. Water Environ Res 79(3):270-278

Pillai SD, Ricke SC (2002) Bioaerosols from municipal and animal wastes: background and contemporary issues. Can J Microbiol 48(8):681-696

Piqueras P, Li F, Castelluccio V, Matsumoto M, Asa-Awuku A (2016) Real-time ultrafine aerosol measurements from wastewater treatment facilities. Environ Sci Technol 50(20):11137-11144

Polska Norma PN-89 Z-04111 02: Ochrona czystosci powietrza. Badania mikrobiologiczne. Oznaczanie liczby bakterii w powietrzu atmosferycznym (imisja) przy pobieraniu probek metoda aspira- $^{-}$ cyjna i sedymentacyjna. Polski Komitet Normalizacji Miar i Jakosci, Warszawa.

Ranalli G, Principi P, Sorlini C (2000) Bacterial aerosol emission from wastewater treatment plants: culture methods and bio-molecular tools. Aerobiologia 16(1):39-46

Reponen T (2011) Methodologies for assessing bioaerosol exposures. Encylopedia Environ Health 3:722-730

Resch FJ, Afeti GM (1992) Submicron film drop production by bubbles in seawater. J Geophys Res 97(C3):3679-3683

Rigaux CS, Carlin F, Nguyen-thé C, Albert I (2013) Inferring an augmented bayesian network to confront a complex quantitative microbial risk assessment model with durability studies: application to bacillus cereus on a courgette purée production chain. Risk Anal 33(5):877-892

Rose JB, Haas CN (1999) A risk assessment framework for the evaluation of skin infections and the potential impact of antibacterial soap washing. Am J Infect Control 27(6):S26-S33

Rosenberg Goldstein RE, Micallef SA, Gibbs SG, Davis JA (2012) Methicillin-resistant Staphylococcus aureus (MRSA) detected at four U.S. wastewater treatment plants. Environ Health Perspect 120(11):1551-1558

Rylander R (2002) Endotoxin in the environment-exposure and effects. J Endotoxin Res 8:241-252

Sanchez-Monedero MA, Aguilar MI, Fenoll R, Roig A (2008) Effect of the aeration system on the levels of airborne microorganisms generated at wastewater treatment plants. Water Res 42(14):3739-3744

Shi KW, Wang CW, Jiang SC (2018) Quantitative microbial risk assessment of Greywater on-site reuse. Sci Total Environ 635(1):1507-1519

Stellacci P, Liberti L, Notarnicola M, Haas CN (2010) Hygienic sustainability of site location of wastewater treatment plants. Desalination 253(1):106-111

Stiles ME (1977) Reliability of selective media for recovery of Staphylococci from cheese. J Food Protect 40(1):11-16

Szyłak-Szydłowski M, Kulig A, Miaskiewicz-Peska E (2016) Seasonal changes in the concentrations of airborne bacteria emitted from a large wastewater treatment plant. Int Biodeterior Biodegradation 115:11-16

Teixeira JV, Miranda S, Monteiro RAR, Lopes FVS, Madureira J, Silva GV, Pestana N, Pinto E, Vilar VJP, Boaventura RAR (2013) Assessment of indoor airborne contamination in a wastewater treatment plant. Environ Monit Assess 185(1):59-72

Thorn J, Beijer L, Rylander R (2002) Work related symptoms among sewage workers: a nationwide survey in Sweden. Occup Environ Med 59:562-566 
Turner S, Hopkinson J, Oxley L, Gadd S, Healey N, Marlow P (2008) Collecting, transfer, treatment and processing household waste and recyclables. HSE Research Report. RR609. Available online: http://www.hse.gov.uk/research/rrhtm/rr609.htm

Uhrbrand K, Schultz AC, Koivisto AJ, Nielsen U, Madsen AM (2017) Assessment of airborne bacteria and noroviruses in air emission from a new highly-advanced hospital wastewater treatment plant. Water Res 112(1):110-119

Vilavert L, Nadal M, Inza I, Figueras MJ, Domingo JL (2009) Baseline levels of bioaerosols and volatile organic compounds around a municipal waste incinerator prior to the construction of a mechanical-biological treatment plant. Waste Manage 29(9):2454-2461

Wathes CM, Zaidan WAR, Pearson GR, Hintonand M, Todd N (1988) Aerosol infection of calves and mice with Salmonella typhimurium. Vet Rec 123:590-594

World Health Organization (2008) Guidelines for drinking-water quality: incorporating 1st and 2nd Addenda. 1. WHO Press, Switzerland
Xiao WJ, Wang ML, Wei W, Wang J, Zhao JJ, Yi B, Li JS (2004) Detection of SARS-CoV and RNA on aerosol samples from SARS-patients admitted to hospital. Chin J Epidemiol 25(10):882-885

Yillia PT, Kreuzinger N, Mathooko JM, Ndomahina ET (2009) Microbial risk assessment with the OAEL approach at water abstraction points in rural Kenya. Phys Chem Earth 34(13):790-798

Zhang MY, Zuo J, Yu X, Shi XC, Chen L, Li ZX (2018) Quantification of multi-antibiotic resistant opportunistic pathogenic bacteria in bioaerosols in and around a pharmaceutical wastewater treatment plant. J Environ Sci 72:53-63

Publisher's Note Springer Nature remains neutral with regard to jurisdictional claims in published maps and institutional affiliations. 